\title{
Outcome Values of Adding Sodium Bicarbonate, Dexamethasone and Fentanyl to Local Anesthetic in Peribulbar Block during Vitreoretinal Surgeries. A Randomized Prospective Study
}

\author{
Sherif Kamal Arafa*, Amir Abouzkry El-Sayed \\ Department of Anesthesia, Faculty of Medicine, Aswan University, Aswan, Egypt \\ Email: *sherifarafa1020@gmail.com
}

How to cite this paper: Arafa, S.K. and El-Sayed, A.A. (2018) Outcome Values of Adding Sodium Bicarbonate, Dexamethasone and Fentanyl to Local Anesthetic in Peribulbar Block during Vitreoretinal Surgeries. A Randomized Prospective Study. Open Journal of Anesthesiology, 8, 1-13. https://doi.org/10.4236/ojanes.2018.81001

Received: December 8, 2017

Accepted: January 26, 2018

Published: January 29, 2018

Copyright $\odot 2018$ by authors and Scientific Research Publishing Inc. This work is licensed under the Creative Commons Attribution International License (CC BY 4.0).

http://creativecommons.org/licenses/by/4.0/

\begin{abstract}
Background and aims: we aimed to detect the outcome values of adding fentanyl, dexamethasone and sodium bicarbonate to mixture of local anesthetic in peribulbar block for vitreoretinal surgery. Methods: 120 adult ASA I \& II patients, admitted for vitreoretinal surgery under peribulbar block were included in this comparative study. This study included 4 groups: Group I: (30) patients using a mixture of $1 \mathrm{ml}$ normal saline, $4 \mathrm{ml}$ lidocaine $2 \%$ plus $4 \mathrm{ml}$ from bupivacaine $0.5 \% 20 \mathrm{ml}$ vial containing hyaluronidase 1500 IU. Group II: (30) patients using a mixture of $1 \mathrm{ml}$ of sodium bicarbonate (from $1 \mathrm{ml}$ sodium bicarbonate $8.4 \%$ diluted in $10 \mathrm{ml}$ normal saline), $4 \mathrm{ml}$ lidocaine $2 \%$ plus $4 \mathrm{ml}$ from bupivacaine $0.5 \% 20 \mathrm{ml}$ vial containing hyaluronidase $1500 \mathrm{IU}$. Group III: (30) patients using a mixture of $1 \mathrm{ml}$ fentanyl $20 \mu \mathrm{g}$ (from a mixture of fentanyl $100 \mu \mathrm{g}$ diluted in $5 \mathrm{ml}$ normal saline), $4 \mathrm{ml}$ lidocaine $2 \%$ plus $4 \mathrm{ml}$ from bupivacaine $0.5 \% 20 \mathrm{ml}$ vial containing hyaluronidase $1500 \mathrm{IU}$. Group IV: (30) patients using a mixture of $1 \mathrm{ml}$ of $4 \mathrm{mg}$ dexamethasone (1 ampoule $=8 \mathrm{mg} / 2 \mathrm{ml}$ ), $4 \mathrm{ml}$ lidocaine $2 \%$ plus $4 \mathrm{ml}$ from bupivacaine $0.5 \% 20$ $\mathrm{ml}$ vial containing hyaluronidase $1500 \mathrm{IU}$. We measured the onset and duration of anesthesia, IOP, eyelid and global akinesia, postoperative pain by numerical pain rating scale, first analgesic requirement and postoperative side effects. Results: No significant differences were detected among the four groups as respect to age, sex and the intraocular pressure (IOP) before the anesthesia block. While the intraocular pressure (IOP) after the anesthesia block there was a significant difference, as IOP was markedly decreased postoperatively in group II compared with other groups. As regard to the onset
\end{abstract}


\& duration of anesthesia there was significant difference among all groups, there was rapid onset and prolonged duration of anesthesia in group III compared with other groups $(1.77 \pm 0.63 \& 5.03 \pm 0.89)$ respectively. As regard the onset of lid akinesia there was significant difference among the four groups with better outcome in group III, as in group III represented the most rapid onset of lid akinesia. As respecting to the onset of global akinesia there was significant difference among the four groups. There was better outcome in group III as it represented more rapid onset of global akinesia compared with other groups. There were significant differences among the four groups as regard postoperative pain all over 6 hours, better results were in group III $(0.27$ $\pm 0.69)$ compared with group I $(2.23 \pm 1.17)$, group II $(2.00 \pm 1.70)$, group IV $(0.67 \pm 0.71)$. As regarding to the first time for analgesic requirement there were significant differences among groups, there was no request for analgesia with better outcome in group III with increasing need to the analgesic medication in group I compared to group II and group IV. As regard side effects postoperatively there were few side effects in all groups with few numbers of cases in groups III only one patient. Although these differences in number of patients are not significant among the four groups. Conclusion: Addition of sodium bicarbonate to local anesthetic mixture was the best way in lowering the IOP other than other groups and addition of fentanyl to local anesthesia provided more rapid onset and duration of anesthesia, more rapid onset and duration for lid and global akinesia, less pain, less analgesic requirement and minimal side effects than the other groups.

\section{Keywords}

Fentanyl, Dexamethasone, Sodium Bicarbonate, Local Anesthesia, Peribulbar Block, Vitreoretinal Surgeries

\section{Introduction}

Vitrectomy is a surgical procedure that obliterates the vitreous in the central cavity of the eye. It is of value in many eye disorders including diabetic eye disease (diabetic retinopathy), retinal detachments, macular hole, trauma and vitreous hemorrhage. Retinal surgery represents an obstacle to the anesthesiologists because of its prolonged duration with postoperative pain [1] [2].

General anesthesia and regional anesthesia are techniques of choice for vitreoretinal surgeries. Regional anesthesia is more preferable as it provides more patients with comfort; lengthy operation, less respiratory depression, less nausea and vomiting as a complication of general anesthesia, decrease postoperative pain and decrease narcotic \& anesthetic consumption. Peribulbar anesthesia is more preferable than retrobulbar for vitreoretinal surgery because of complications of the retrobulbar block as retrobulbar apnea, risk of perforation and central spread up to cardiac arrest [3].

Fentanyl (N-phenyl-N-(1-Phenethyl-4-piperi-dinyl) propanamide) is an opioid 
analgesic with potency 80 times that of morphine with a rapid onset and short time of duration of action. It is a potent agonist of $\mu$-opioidreceptors. Fentanyl was first described by Paul Janssen in 1960 [4].

Hyaluronidase (an enzyme) catalyzes the depolymerization of hyaluronic acid to a tetra saccharide that improves the efficacy of local anesthetics by breaking down interstitial cell barriers, facilitating diffusion of the anesthetic solution and lowering the intraocular pressure [5].

Dexamethasone is a high potency, long acting glucocorticoid with little mineralocorticoid effect. Glucocorticoids have been used to decrease inflammation and prevention of postoperative nausea and vomiting; minimizing postoperative pain, edema and prolong duration effects of local anesthesia [6].

Sodium bicarbonate increases drug penetration through the soft tissues and nerve sheath, decreasing the duration of onset of action. The use of sodium bicarbonate with local anesthetic for vitrectomy surgery is safe and effective with respect to early onset and complete ocular anesthesia and reducing IOP [7] [8].

\section{Patients and Methods}

After approval of the departmental ethical committee, and after doing the Pan African Clinical Trial Registry (http://www.pactr.org/) database, my unique identification number for the registry is PACTR 201712002860265. This study was conducted at Aswan University Hospital for 6 months from December 2016 to May 2017. We studied on 120 adult patients of both sexes those who were scheduled to undergo elective vitrectomy surgery. Prospective randomized comparative hospital-based clinical study. Randomization was done by system of computer used for creation of a list of numbers, each number referred to one of four groups, Then opaque envelope used to seal each number, then we asked the patient to choose one of the envelopes and the anesthesiologist take the envelopes from the patients. The anesthesiologist compared the number with computer generated list and ordered the patients to one of the four groups. Anesthesiologist is one who was preparing the drug solution and labeled it and gave them to another anesthesiologist that responsible for the peribulbar block and collected the data while he was blinded to the content of the syringes. The signed informed consent form was a permanent part of the participant's study records and saved in the same manner as other records. All patients were informed by hazards and benefits of peribulbar block. Patients participated in this study were American Society of Anesthesiology (ASA) I or II patients, aged 40 - 60 years old. While patients with ASA III or IV, Uncooperative patients, Allergic to medication used, patient refusal, coagulopathy or history of anticoagulant therapy, patient with neurological manifestations, orbital deformity, failed regional block, high myopic patients with axial length more than $28 \mathrm{~mm}$, active respiratory disease, poor communication ability as deafness or mute, patients with excessive tremors or agitations, one eyed patients, and patients with glaucoma were excluded from this study. 
Electrocardiography, complete blood picture, coagulation profile, hepatic functions and renal functions tests were done for every patient. In operating room, an intravenous line was inserted, basic monitors were applied (5-lead ECG, pulse oximetery, non-invasive blood pressure "NIBP"), and a nasal cannula $2 \mathrm{~L} / \mathrm{min}$ were attached. All patients were premedicated with $30 \mathrm{mg}$ propofol and $1 \mathrm{mg}$ mediathetic (midazolam). Monitoring and oxygen therapy were continued for all patients throughout the procedure. All patient were received infra-nasal approach (peribulbar block) using small short needle 25 gauge, 5/8 inch to reduce sense of pain during puncture, reduce incidence of ecchymosis after puncture and send a good impact to patients about local anesthesia and the more simplicity of it and not leave bad memory with him. After negative aspiration to avoid intravascular injection, local anesthetic mixtures were given. All patients were received total volume of local anesthetic mixture $9 \mathrm{ml}$. Topical anesthesia to all patients was done by Benoxinate hydrochloride $0.4 \%$ and intra ocular pressure documented before starting LA.

120 Patients were randomly allocated into four groups (30 each) using closed envelopes methods:

Group I: 30 patients using a mixture of $1 \mathrm{ml}$ normal saline, $4 \mathrm{ml}$ lidocaine $2 \%$ plus $4 \mathrm{ml}$ from bupivacaine $0.5 \%$ ( $20 \mathrm{ml}$ vial containing hyaluronidase $1500 \mathrm{IU}$ ).

Group II: 30 patients using a mixture of $1 \mathrm{ml}$ of sodium bicarbonate (from 1 $\mathrm{ml}$ sodium bicarbonate $8.4 \%$ diluted in $10 \mathrm{ml}$ normal saline), $4 \mathrm{ml}$ lidocaine $2 \%$ plus $4 \mathrm{ml}$ from bupivacaine $0.5 \%$ ( $20 \mathrm{ml}$ vial containing hyaluronidase $1500 \mathrm{IU}$ ).

Group III: 30 patients using a mixture of $1 \mathrm{ml}$ fentanyl $20 \mu \mathrm{g}$ (from a mixture of fentanyl $100 \mu \mathrm{g}$ diluted in $5 \mathrm{ml}$ normal saline), $4 \mathrm{ml}$ lidocaine $2 \%$ plus $4 \mathrm{ml}$ from bupivacaine $0.5 \%$ (20 ml vial containing hyaluronidase $1500 \mathrm{IU})$.

Group IV: 30 patients using a mixture of $1 \mathrm{ml}$ of $4 \mathrm{mg}$ dexamethasone (1 ampoule $=8 \mathrm{mg} / 2 \mathrm{ml}$ ), $4 \mathrm{ml}$ lidocaine $2 \%$ plus $4 \mathrm{ml}$ from bupivacaine $0.5 \%$ (20 $\mathrm{ml}$ vial containing hyaluronidase $1500 \mathrm{IU})$.

Immediately after injection 3 - 5 min pressure applied using Honan balloon sets at $25 \mathrm{mmHg}$ to closed eye to promote spread of the local anesthetic and to decrease intraocular pressure.

\subsection{Primary Outcome}

Primary outcomes were the intraocular pressure, onset of anesthesia, duration of anesthesia and duration of akinesia for both eyelid and globe.

\subsection{Secondary Outcome}

Secondary outcomes were included postoperative pain assessment by numerical pain rating scale, first requirement for analgesia and any adverse effects could be detected as nausea, vomiting, redness, peribulbar edema and headache postoperatively.

Intraocular pressure (IOP) before and after block were recorded using Schiotz tonometer. The onset of anesthesia (from starting the injection till loss of corneal reflex in response to touching cornea surface with cotton tips) and the du- 
ration of the anesthesia (the time from loss of corneal sensation till return of corneal sensation) were recorded.

For assessment of onset of lid akinesia, the patients were asked to open their eyelids and then squeeze them together maximally at 1, 3, 5, 8 minutes. Grade 0 = Complete akinesia, grade 1 = Partial movement in either or both eyelid margins, grade $2=$ Normal movement in either or both eyelid margins.

Globe akinesia on set was assessed by examination of the movements of the extra-ocular muscles in all of the 4 main directions (superior, inferior, medial and lateral) using a 3 point scoring system at $1,3,5,8$ minutes. $0=$ no movement at all, $1=$ partial movement in one or two directions, $2=$ free movement in all directions giving an aggregated score ranging from zero to 8 for the 4 direction. The block will be considered to be satisfactory when global akinesia score of 3 or less not more than 1 in each direction [9].

Duration of akinesia (the time started from maximum akinesia of both eyelid and eye till start to move both freely respectively) were also recorded.

Postoperative pain was recorded by using the numeric pain rating scale every hour up to $6 \mathrm{~h}$ postoperatively as follows:

$0=$ no pain,

1,2 and 3 = mild pain,

4,5 and $6=$ moderate pain,

7,8 and $9=$ severe pain,

$10=$ very severe pain or maximum pain imaginable.

If the numeric pain rating scale was more than 3, Perflgan IV was given. The time for first need for analgesia was also recorded. Any adverse effects could be also detected as nausea, vomiting, redness, peribulbar edema and headache postoperatively.

\subsection{Power of Study}

The previous study reported that the mean IOP after the block was $20.06 \pm 1.88$, the mean of onset of anesthesia was $2.81 \pm 0.97$, the mean of duration of anesthesia was $3.62 \pm 1.18$ and the mean of duration of akinesia for both globe and eyelids were $3.25 \pm 1.11$ ( $11 \& 12 \& 17$ ). Based on our study on 120 patients 30 in each group were required to detect a statistically significant difference between groups in our primary outcome parameters, supposing an alpha error of 0.05 and power of $80 \%$. We aimed to study 30 patients in each group (Figure 1).

\subsection{Statistical Analysis}

The full detailed form is: SPSS 20, IBM, and Armonk, NY, United States of America.

Quantitative data were expressed as mean \pm standard deviation (SD). Qualitative data were expressed as frequency and percentage.

- A one-way analysis of variance (ANOVA) when comparing between more than two means. 

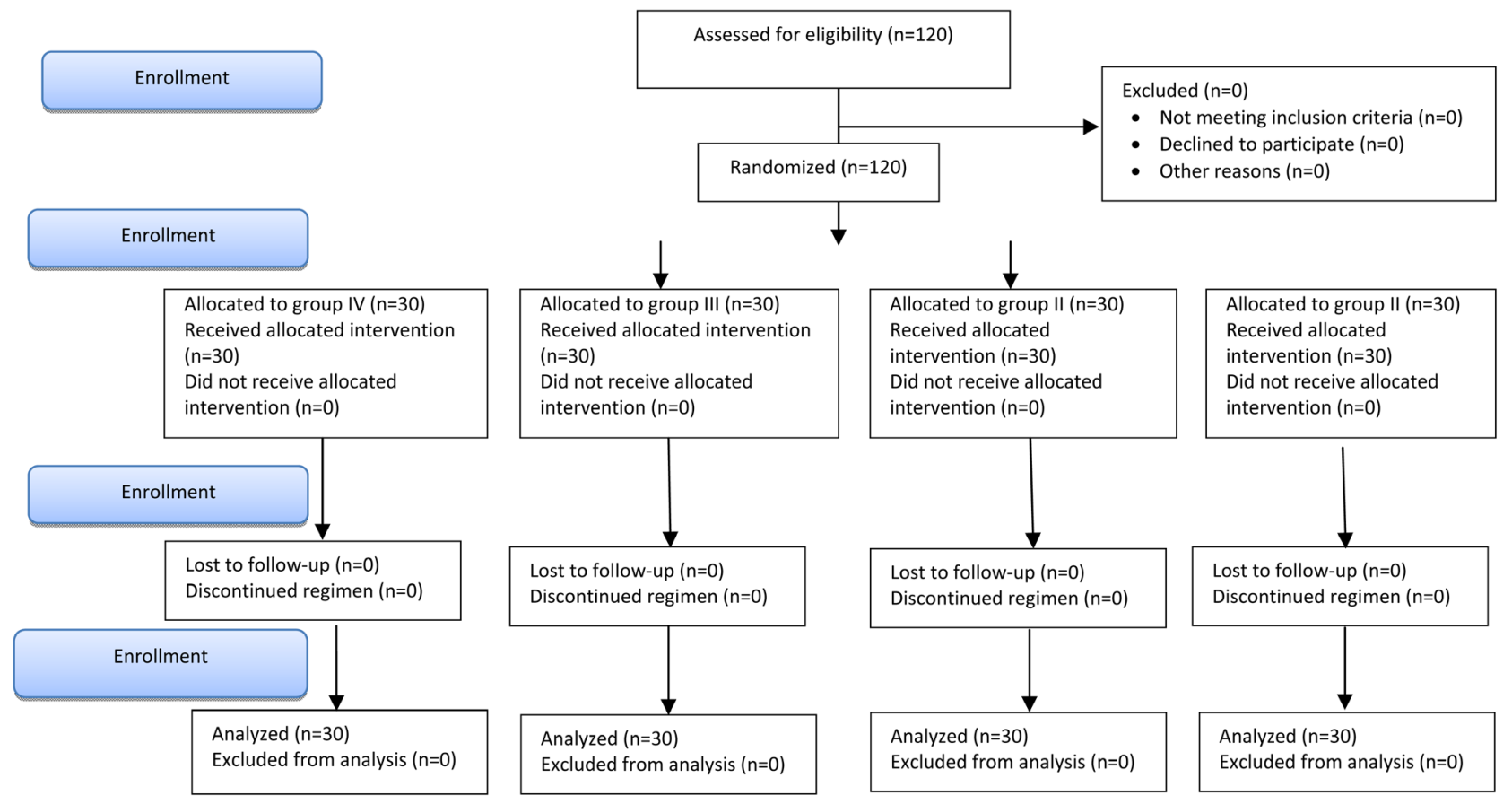

Figure 1. Flow of participant groups.

- Chi-square (X2) test of significance was used in order to compare proportions between two qualitative parameters.

\section{Results}

Our study results were classified into preoperative, operative and postoperative data. As regarding the preoperative data, no significant differences were detected between four groups as regarding age, sex and the intraocular pressure (IOP) before the anesthesia block. While the intraocular pressure (IOP) after the anesthesia block there was a significant differences, as IOP was markedly decreased postoperatively in group II compared with other groups. As regard the onset of anesthesia there was significant differences between all groups, there was more rapid onset of anesthesia in group III compared with other groups $(1.77 \pm 0.63)$ (Table 1).

\subsection{Pre Operative Data}

See Table 1.

\subsection{Operative Data}

As regarding to the onset of lid akinesia there was significant changes between four groups.

With better outcome in group III, as in Group III represented the most rapid onset of lid akinesia as 30 patients of this group had a complete lid akinesia at 3 minutes as compared with other groups. Group I at $1 \mathrm{~min} \& 3 \mathrm{~min} \& 5 \min \&$ 
Table 1. Comparison between four groups as regard sex, age, intraocular pressure (IOP before block \& after block) and onset of anesthesia.

\begin{tabular}{cccccc}
\hline & G I & G II & G III & G IV & $p$-value \\
\hline Sex M/F & $20 / 10$ & $18 / 12$ & $17 / 13$ & $17 / 13$ & 0.841 \\
Age & $48.60 \pm 5.96$ & $48.40 \pm 6.30$ & $48.83 \pm 5.83$ & $50.43 \pm 6.36$ & 0.559 \\
IOP before block & $21.28 \pm 2.10$ & $21.49 \pm 1.89$ & $21.25 \pm 1.81$ & $21.09 \pm 2.0$ & 0.888 \\
IOP after block & $21.14 \pm 2.14$ & $18.65 \pm 1.57$ & $20.06 \pm 1.53$ & $21.22 \pm 1.66$ & $0.001^{*}$ \\
Onset of anesthesia & $3.77 \pm 0.90$ & $2.57 \pm 0.50$ & $1.77 \pm 0.63$ & $3.60 \pm 0.89$ & $0.001^{\star}$ \\
\hline
\end{tabular}

Data are presented as mean \pm S.D; ${ }^{*}$ Statistical significant $\mathrm{P}$ value $<0.05$.

$8 \min =0 \%, 0 \%, 50 \%, 50 \%$ respectively. Group II at $1 \min \& 3 \min \& 5 \min \& 8$ $\min =16.7 \%, 36.7 \%, 46.7 \%, 0 \%$ respectively. Group III at $1 \min \& 3 \min \& 5$ $\min \& 8 \min =10 \%, 90 \%, 0 \%, 0 \%$ respectively. Group IV at $1 \min \& 3 \min \& 5$ $\min \& 8 \min =0 \%, 0 \%, 93.3 \%, 6.7 \%$ respectively (Table 2 and Figure 2 ).

As regard the onset of global akinesia there was significant differences between four groups. There was better outcome in group III as it represented more rapid onset of global akinesia compared with other groups. As 30 patients had complete global akinesia at $5 \mathrm{~min}$ with only 7 patients at 5 min compared to group II that had 11 patients (GIII $>$ GII). Group I at $1 \min \& 3 \min \& 5 \min \&$ $8 \min =0 \%, 13.3 \%, 46.7 \%, 40 \%$ respectively. Group II at $1 \min \& 3 \min \& 5 \min$ $\& 8 \min =3.3 \%, 60 \%, 36.7 \%, 0 \%$ respectively. Group III at $1 \mathrm{~min} \& 3 \min \& 5$ $\min \& 8 \min =13.3 \%, 63.3 \%, 23.3 \%, 0 \%$ respectively. Group IV at $1 \mathrm{~min} \& 3 \mathrm{~min}$ $\& 5 \min \& 8 \mathrm{~min}=0 \%, 20 \%, 63.3 \%, 16.7 \%$ respectively (Table 3 and Figure 3 ).

There were significant differences between four groups as regard duration of anesthesia and akinesia for both eyelids and eye ball, with more prolonged duration of anesthesia and akinesia in group III compared with other groups (5.03 \pm $0.89 \& 4.62 \pm 0.62$ ) respectively (Table 4 ).

\subsection{Post-Operative Data}

There were significant differences between four groups as regard postoperative pain all over 6 hours, better results were in group III compared with other groups $(0.27 \pm 0.69)$ (Table 5 and Figure 4$)$. As regard the first time for analgesic requirement there were significant differences between groups, there was no request for analgesic medications with better outcome in group III with increasing the request to analgesic medications in group I compared to group II and group IV (Table 5 and Figure 4).

As regard side effects postoperatively there were few side effects in all groups with few numbers of cases in groups III; only one patients. Although this differences in number of patients there were no significant changes between four groups. In groups I, there were 4 patients with nausea, vomiting peribulbar edema and eye redness. IN group II, there were 3 patients with nausea, headache, and redness. IN group III, there was only one patient with vomiting. IN group IV, there were 4 patients with vomiting, headache, lid edema and burning sensation (Table 6). 
$\%$

Onset of lid akinesia

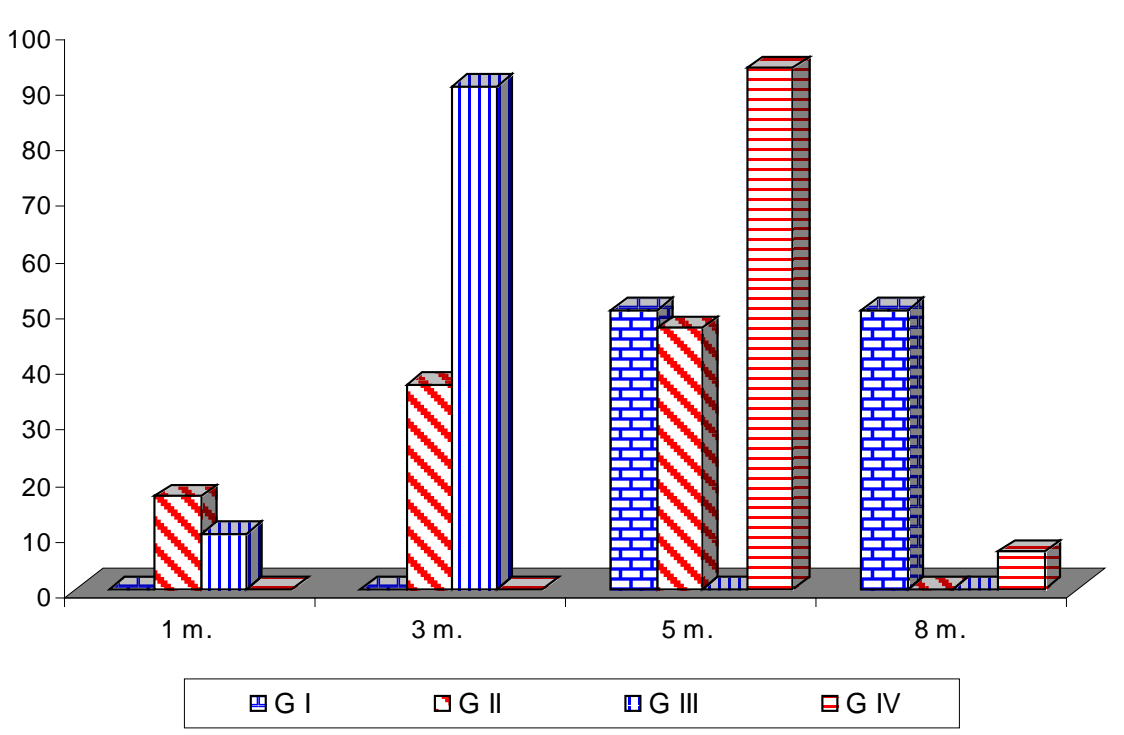

Figure 2. Comparison between four groups in onset of lid akinesia having grade 0 akinesia (complete akinesia).

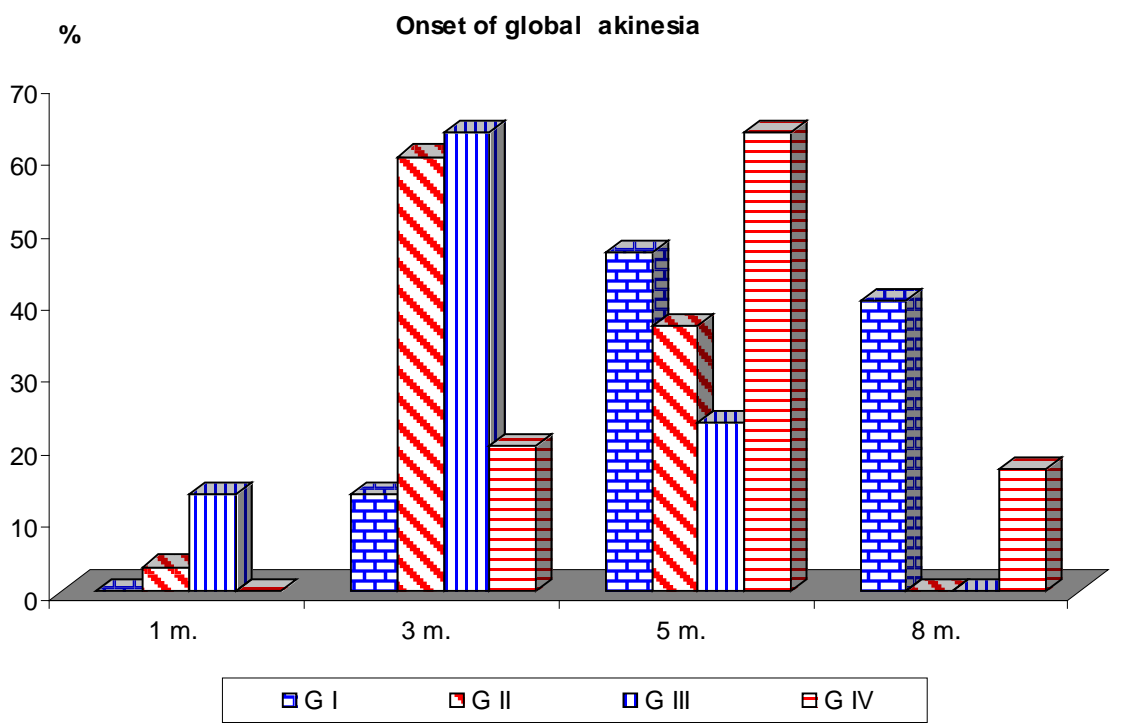

Figure 3. Comparison between four groups in onset of globe akinesia having grade 0 akinesia (complete akinesia).

Table 2. Comparison between four groups in onset of lid akinesia having grade 0 akinesia (complete akinesia).

\begin{tabular}{|c|c|c|c|c|c|c|c|c|c|c|}
\hline \multirow{2}{*}{$\begin{array}{l}\text { Onset of lid } \\
\text { akinesia }\end{array}$} & \multicolumn{2}{|c|}{ G I } & \multicolumn{2}{|c|}{ G II } & \multicolumn{2}{|c|}{ G III } & \multicolumn{2}{|c|}{ G IV } & \multirow{2}{*}{$\mathrm{X}^{2}$} & \multirow{2}{*}{$P$-value } \\
\hline & $\mathrm{N}$ & $\%$ & $\mathrm{~N}$ & $\%$ & $\mathrm{~N}$ & $\%$ & $\mathrm{~N}$ & $\%$ & & \\
\hline $1 \mathrm{~m}$ & 0 & 0 & 5 & 16.7 & 3 & 10 & 0 & 0 & 9.643 & $0.022^{\star}$ \\
\hline $3 \mathrm{~m}$ & 0 & 0 & 11 & 36.7 & 27 & 90 & 0 & 0 & 75.332 & $0.001^{*}$ \\
\hline $5 \mathrm{~m}$ & 15 & 50 & 14 & 46.7 & 0 & 0 & 28 & 93.3 & 52.503 & $0.001^{*}$ \\
\hline $8 \mathrm{~m}$ & 15 & 50 & 0 & 0 & 0 & 0 & 2 & 6.7 & 42.792 & $0.001^{\star}$ \\
\hline
\end{tabular}

* Statistical significant $P$ value $<0.05$. 


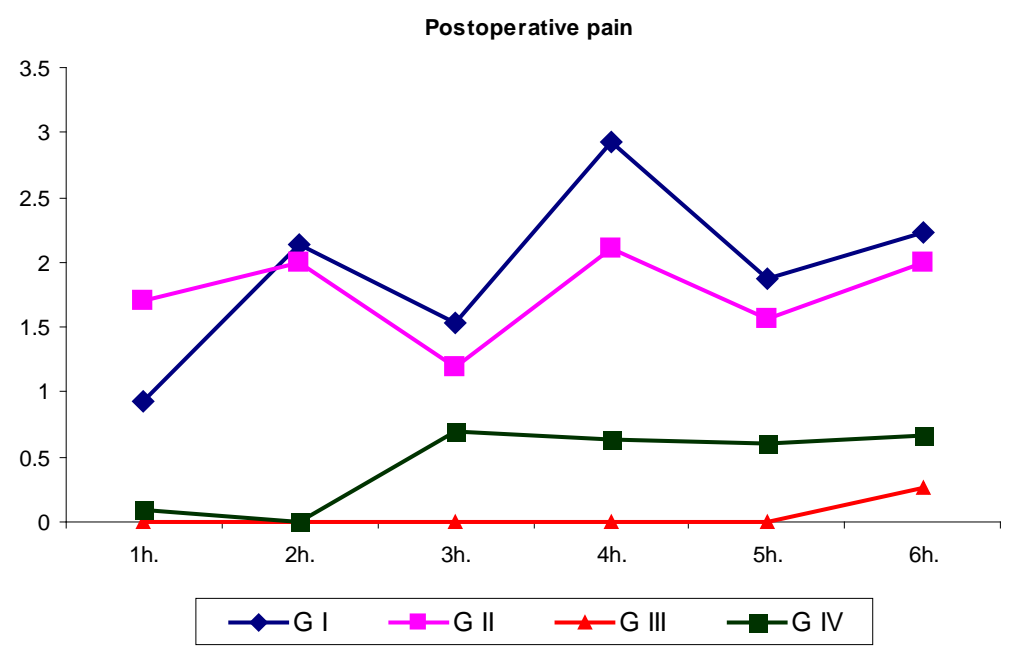

Figure 4. Comparison between four groups for post-operative pain using numerical rating scale (NRS).

Table 3. Comparison between four groups in onset of globe akinesia having grade 0 akinesia (complete akinesia).

\begin{tabular}{ccccccccccc}
\hline \multirow{2}{*}{$\begin{array}{c}\text { Onset of } \\
\text { global } \\
\text { akinesia }\end{array}$} & \multicolumn{2}{c}{ G I } & \multicolumn{2}{c}{ G II } & \multicolumn{2}{c}{ G III } & \multicolumn{2}{c}{ G IV } & \multirow{2}{*}{$\mathrm{X}^{2}$} & $P$-value \\
\cline { 2 - 8 } & $\mathrm{N}$ & $\%$ & $\mathrm{~N}$ & $\%$ & $\mathrm{~N}$ & $\%$ & $\mathrm{~N}$ & $\%$ & & \\
\hline $1 \mathrm{~m}$ & 0 & 0 & 1 & 3.3 & 4 & 13.3 & 0 & 0 & 8.971 & $0.030^{*}$ \\
$3 \mathrm{~m}$ & 4 & 13.3 & 18 & 60 & 19 & 63.3 & 6 & 20 & 25.582 & $0.001^{*}$ \\
$5 \mathrm{~m}$ & 14 & 46.7 & 11 & 36.7 & 7 & 23.3 & 19 & 63.3 & 10.472 & $0.015^{*}$ \\
$8 \mathrm{~m}$ & 12 & 40 & 0 & 0 & 0 & 0 & 5 & 16.7 & 26.523 & $0.022^{*}$ \\
\hline
\end{tabular}

*Statistical significant $P$ value $<0.05$.

Table 4. Comparison between four groups for duration of anesthesia and akinesia for both eyelids \& globe.

\begin{tabular}{cccccc}
\hline & G I & G II & G III & G IV & $p$-value \\
\hline $\begin{array}{c}\text { Duration of akinesia } \\
\text { for eyelid and eye }\end{array}$ & $2.28 \pm 0.49$ & $2.43 \pm 0.50$ & $4.62 \pm 0.62$ & $3.73 \pm 0.64$ & $0.001^{\star}$ \\
$\begin{array}{c}\text { Duration of anesthesia } \\
\text { Dun }\end{array}$ & $2.92 \pm 0.66$ & $2.63 \pm 0.60$ & $5.03 \pm 0.89$ & $3.93 \pm 0.69$ & $0.001^{*}$ \\
\hline
\end{tabular}

Data are presented as mean \pm S.D; ${ }^{\star}$ Statistical significant $P$ value $<0.05$.

Table 5. Comparison between four groups for post-operative pain using numerical rating scale (NRS).

\begin{tabular}{|c|c|c|c|c|c|}
\hline Postoperative pain & G I & G II & G III & G IV & $p$-value \\
\hline $1 \mathrm{~h}$ & $0.93 \pm 1.72$ & $1.70 \pm 1.84$ & $0.00 \pm 0.00$ & $0.10 \pm 0.31$ & $0.001^{*}$ \\
\hline $2 \mathrm{~h}$ & $2.13 \pm 2.08$ & $2.00 \pm 1.58$ & $0.00 \pm 0.00$ & $0.00 \pm 0.00$ & $0.001^{*}$ \\
\hline $3 \mathrm{~h}$ & $1.53 \pm 1.22$ & $1.20 \pm 0.55$ & $0.00 \pm 0.00$ & $0.70 \pm 0.95$ & $0.001^{\star}$ \\
\hline $4 \mathrm{~h}$ & $2.93 \pm 1.41$ & $2.10 \pm 1.79$ & $0.00 \pm 0.00$ & $0.63 \pm 0.49$ & $0.001^{*}$ \\
\hline $5 \mathrm{~h}$ & $1.87 \pm 0.86$ & $1.57 \pm 0.82$ & $0.00 \pm 0.00$ & $0.60 \pm 0.50$ & $0.001^{\star}$ \\
\hline $6 \mathrm{~h}$ & $2.23 \pm 1.17$ & $2.00 \pm 1.70$ & $0.27 \pm 0.69$ & $0.67 \pm 0.71$ & $0.001^{*}$ \\
\hline $\begin{array}{l}\text { Time for first } \\
\text { analgesic requirement }\end{array}$ & $2.33 \pm 2.09$ & $2.10 \pm 1.24$ & $0.00 \pm 0.00$ & $0.87 \pm 0.94$ & $0.001^{\star}$ \\
\hline
\end{tabular}


Table 6. Comparison between four groups for postoperatively adverse effects.

\begin{tabular}{ccccccccccc}
\hline \multirow{2}{*}{ Side effect } & \multicolumn{2}{c}{ G I } & \multicolumn{2}{c}{ G II } & \multicolumn{2}{c}{ G III } & \multicolumn{2}{c}{ G IV } & \multirow{2}{*}{$\mathrm{X}^{2}$} & $P$-value \\
\cline { 2 - 9 } & $\mathrm{N}$ & $\%$ & $\mathrm{~N}$ & $\%$ & $\mathrm{~N}$ & $\%$ & $\mathrm{~N}$ & $\%$ & & \\
\hline Yes & 4 & 13.3 & 3 & 10 & 1 & 3.3 & 4 & 13.3 & \multirow{2}{*}{2.222} & 0.528 \\
No & 26 & 86.7 & 27 & 90 & 29 & 96.7 & 26 & 86.7 & & \\
\hline
\end{tabular}

${ }^{*}$ Statistical significant $P$ value $<0.05$.

\section{Discussion}

Our study aimed to detect the outcome values of adding fentanyl, dexamethasone and sodium bicarbonate to mixture of local anesthetic in peribulbar block for vitreoretinal surgery. With primary outcomes were the intraocular pressure and onset of anesthesia. While secondary outcomes were included the duration of anesthesia, duration of global and eyelid akinesia, postoperative pain assessment by numerical pain rating scale, first need for analgesia postoperatively. The supplementation of hyaluronidase to local anesthetic mixtures decreases time of the onset for peribulbar block and quality of akinesia in most reported studies [10]. Hyaluronidase catalyses the depolymerization of hyaluronic acid to a tetrasaccharidde and leads to liquefaction of the gelatinous interstitial barrier [5]. In our study it was found that sodium bicarbonate buffered anesthetic mixture was as safe and effective in lowering the intraocular pressure postoperatively compared to other groups, it has short time of onset of anesthesia with complete lid and globe akinesia at 5 minutes after group III (fentanyl group). With increasing pain perception one hour postoperatively compared to other groups. The results of the present study are in accordance with study done by Col RP Gupta, et al. [11]. Galindo et al. [12] documented that by altering the $\mathrm{pH}$ of the local anesthetic solution with sodium bicarbonate, in a 1:10 mixture with lidocaine orbupivacaine, the time for the onset could be decreased and the distribution of neural blockade enhanced significantly.

The alkaline form of the drug is active and alkanisation with sodium bicarbonate increases the non-cation form of the drug [7] [8]. Zahl $\mathrm{K}$ et al. postulated that the non-cation form penetrates the soft tissue and nerve sheath faster resulting in reduction in duration of the onset of action [8]. Fentanyl has analgesic effects through central receptor to the brain and spinal cord [13] and has a direct action on peripheral opioid receptors [14] [15]. So fentanyl enhances the efficacy of local anesthetic drugs [16]. Our results reported the evidence that addition of fentanyl to anesthesia mixture provide more rapid onset and duration of anesthesia \& rapid onset of eyelid akinesia and duration for both lid and global akinesia \& less pain perception and less need for analgesia. Poonam Nehra et al. [17] compared the addition of fentanyl versus clonidine (selective alpha 2 agonist) to local anesthetic mixture in peribulbar block and reported that the onset time of globe akinesia was significantly shorter in fentanyl group (F) and clonidine group (C) compared to control group (S). They also documented that the durations of motor block and analgesia were significantly longer in Group F and group $\mathrm{C}$ compared to group S. The results of the present study are in accordance 
with study done by Toshiharu et al. [18] who studied the effect of supplementation of fentanyl to mepivacaine in epidural block and found that addition of fentanyl to mepivacaine accelerate the onset of analgesia and enhances the analgesic effect of epidural block. Deniz et al. [19] found that application of fentanyl to bupivacaine in brachial plexus axillary approach potentiates anesthesia and analgesia, prolong duration of sensory and motor block and improves the duration of postoperative analgesia. In the present study the first time to require analgesia was prolonged in Fentanyl group, in which only eight patients required rescue analgesia after 6 hours postoperative while in other groups required analgesia in first hour. These results are similar to the results of constant $\mathrm{O}$ et al. [20] who documented the effect of addition of fentanyl to local anesthetic mixture in caudal block in children underwent bilateral vesico-ureteral reflux and they found that addition of fentanyl $\left(1 \mathrm{mcg} \cdot \mathrm{kg}^{-1}\right)$ to bupivacaine $0.25 \%$ and lidocaine $1 \%$ prolong duration of surgical analgesia after single injection from start of injection to first need for analgesic medications from $174 \mathrm{~min}$ in Control group to $253 \mathrm{~min}$ in Fentanyl group. In the present study fentanyl group had minimal pain score postoperatively than in other groups. IN cooperation with the study done by Vita et al. [21] who found that intra-articular injection of fentanyl enhance postoperative pain and no different changes between intra-articular morphine and fentanyl in postoperative pain relief. Dexamethasone was not used before as an adjuvant to local anesthetic for ophthalmic block but used alone intravitreally, subconjunctival, and in peribulbar injection [22]. Local steroid application had the effect to inhibit transmission in thin unmyelinated $\mathrm{C}$ fibers [23]. Our study reported that dexamethasone group had long duration of anesthesia, duration of akinesia, delayed pain perception, less analgesic requirements after fentanyl group, delayed onset of lid akinesia till 5 minutes and global akinesia at 3 minutes. Shrestha et al. [24] found that dexamethasone added to local anesthetic prolongs postoperative analgesia significantly compared with tramadol when used as an admixture to a local anesthetic in brachial plexus block in upper extremity surgery, and Parrington et al. [25] also found that the supplementation of dexamethasone to mepivacaine enhances the duration of analgesia but does not reduce the onset of sensory and motor blockade after ultrasound guided supraclavicular block compared with mepivacaine alone.

\section{Conclusion}

Addition of sodium bicarbonate to local anesthetic mixture was the best way in lowering the IOP other than other groups and addition of fentanyl to local anesthesia provided more rapid onset and duration of anesthesia, more rapid onset and duration for lid and global akinesia, less pain, less analgesic requirement and less adverse effects postoperatively than the other groups.

\section{Limitations of the Study}

There was no control group but our study proved that the drugs were used potentiates the effects of local anesthetic mixtures. The other point was that doses 
of dexamethasone, fentanyl and sodium bicarbonate, we used close to that used in previous studies but the exact doses to give better result and outcome is still not clear and this may be a point for further research. We think that the previous limitation of our study did not affect the strength of the study.

\section{Conflict of Interests}

No conflict of interests.

\section{References}

[1] MacHemer, R. (1995) The Development of Pars Planavitrectomy: A Personal Account. Graefe's Archive for Clinical and Experimental Ophthalmology = Albrecht von Graefes Archivfürklinische und Experimental Ophthalmology, 233, 453-468. https://doi.org/10.1007/BF00183425

[2] Newsom, R.S., Wainwright, A.C. and Canning, C.R. (2001) Local Anesthesia for 1221 Viteoretinal Procedures. British Journal of Ophthalmology, 85, 225-227. https://doi.org/10.1136/bjo.85.2.225

[3] Eke, T. and Thompson, J.R. (1990) The National Survey of Local Anesthesia for Ocular surgery. II. Safety Profiles of Local Anesthesia Techniques. Eye, 13, 196-204. https://doi.org/10.1038/eye.1999.50

[4] Abo El Enin, M.A., Amin, I.E., Abd El Aziz, A.S., Mahdy, M.M., Abo El Enin, M.A., et al. (2009) Effect of Fentanyl Addition to Local Anaesthetic in Peribulbar Block. Indian Journal of Anaesthesia, 53, 57-63.

[5] Mindel, J.S. (1978) Value of Hyaluriondase in Ocular Surgival Akinesia. American Journal of Ophthalmology, 85, 643-646. https://doi.org/10.1016/S0002-9394(14)77097-7

[6] Gan, T.J., Meyer, T., Apfel, C.C., Chung, F., Davis, P.J., Eubanks, S., Kovac, A., Philip, B.K., Sessler, D.I., Temo, J., Tramer, M.R. and Watcha, M. (2003) Department of Anesthesiology, Consensus Guidelines for Managing Postoperative Nausea and Vomiting. Anesthesia \& Analgesia, 97, 62-71. https://doi.org/10.1213/01.ANE.0000068580.00245.95

[7] Havener, W.H. (1994) Ocular Pharmacology. 6th Edition, St. Louis, CV Mosby Company, 201-233.

[8] Zahl, K., Jordan, A., McGroarty, J., Sorenson, B. and Gotta, A.W. (1991) Peribulbar Anesthesia-Effect of Bicarbonate on Mixtures of Lidocaine, Bupivacaine and Hyaluronidase with or without Epinephrine. Ophthalmology, 98, 239-242. https://doi.org/10.1016/S0161-6420(91)32311-X

[9] Frow, M.W., Miranda-Caraballo, J.I., Akhtar, T.M. and Hugkulstone, C.E. (2000) Single Injection Peribulbaranaesthesia, Total Upper Eyelid Drop as Anendpoint Marker. Anaesthesia, 55, 750-756. https://doi.org/10.1046/j.1365-2044.2000.01530.x

[10] Sarvela, J. and Nikki, P. (1992) Hyaluronidase Improves Regional Ophthalamicanaesthesia with Etidocaine. Canadian Journal of Anesthesia, 39, 920-924. https://doi.org/10.1007/BF03008340

[11] Col, R.P. and Maj, G. (2006) Safety and Efficacy of Sodium Bicarbonate versus Hyaluronidase in Peribulbaranaesthesia. Medical Journal Armed Forces India, 62, 116-118. https://doi.org/10.1016/S0377-1237(06)80050-X

[12] Galindo, A. (1983) Ph Adjusted Local Anaesthetic: Clinical Experience. Regional Anesthesia, 8, 35-40. 
[13] Millan, M.J. (1986) Multiple Opioid Systems and Pain. Pain, 27, 303-347. https://doi.org/10.1016/0304-3959(86)90158-2

[14] Stein, C. and Lang, L.J. (2009) Peripheral Mechanisms of Opioid Analgesia. Current Opinion in Pharmacology, 9, 3-8. https://doi.org/10.1016/j.coph.2008.12.009

[15] Sehgal, N., Smith, H.S. and Manchikanti, L. (2011) Peripherally Acting Opioids and Clinical Implications for Pain Control. Pain Physician, 14, 249-258.

[16] Gissen, A.J., Gugino, L.D., Datta, S., Miller, J. and Covino, B.G. (1987) Effects of Fentanyl and Sufentanil on Peripheral Mammalian Nerves. Anesthesia \& Analgesia, 66, 1272-1276. https://doi.org/10.1213/00000539-198712000-00012

[17] Nehra, P., Oza, V., Parmar, V. and Fumakiya, P. (2017) Effect of Addition of Fentanyl and Clonidine to Local Anesthetic Solutionin Peribulbar Block. Journal of Pharmacology and Pharmacotherapeutics, 8, 3-7. https://doi.org/10.4103/jpp.JPP_109_16

[18] Kasaba, T., Yoshikawa, G., Seguchi, T. and Takasaki, M. (1996) Epidural Fentanyl Improves the Onset and Spread of Epidural Mepivacaine Analgesia. Canadian Journal of Anesthesia, 43, 1211-1215. https://doi.org/10.1007/BF03013426

[19] Karakaya, D., Büyükgöz, F., Baré, S., et al. (2001) Addition of Fentanyl to Bupivacaine Prolongs Anesthesia and Analgesia in Axillary Brachial Plexus Block. Canadian Journal of Anesthesia, 26, 434-438.

[20] Consant, O., Gall, L. and Chawin, M.I. (1998) Addition of Fentanyl to Local Anaesthetics Prolongs the Duration of Surgical Analgesia after Single Shot Caudal Block in Children. British Journal of Anaesthesia, 80, 294-298. https://doi.org/10.1093/bja/80.3.294

[21] Vita varkel, G., Bruce, B.D., et al. (1999) Intraarticular Fentanyl Compared with Morphine for Pain Relief Following Arthroscopic Knee Surgery. Canadian Journal of Anesthesia, 46, 867-871. https://doi.org/10.1007/BF03012977

[22] Weijtens, O., Feron, E.J., Schoemaker, R.C., et al. (1999) High Concentration of Dexamethasone in Aqueous and Vitreous after Subconjunctival Injection. American Journal of Ophthalmology, 128, 192-197. https://doi.org/10.1016/S0002-9394(99)00129-4

[23] Johansson, A., Hao, J. and Sjolund, B. (1990) Local Corticosteroid Application Blocks Transmission in Normal Nociceptive C-Fibres. Acta Anaesthesiologica Scandinavica, 34, 335-338. https://doi.org/10.1111/j.1399-6576.1990.tb03097.x

[24] Shrestha, B.R., Maharjan, S.K., Shrestha, S., et al. (2007) Comparative Study between Tramadol and Dexamethasone as an Admixture to Bupivacaine in Supraclavicular Brachial Plexus Block. Journal of Nepal Medical Association, 46, 158-164.

[25] Parrington, S.J., O’Donnell, D., Chan, V.W., et al. (2010) Dexamethasone Added to Mepivacaine Prolongs the Duration of Analgesia after Supraclavicular Brachial Plexus Blockade. Regional Anesthesia and Pain Medicine, 35, 422-426.

https://doi.org/10.1097/AAP.0b013e3181e85eb9 